\begin{tabular}{l|l|c}
\hline \hline Vol. 30(2):193-205 & Ocean and Polar Research & June 2008 \\
\hline \hline
\end{tabular}

\title{
Article
}

\section{Seasonal Volume Transport Variation and Origin of the Tsushima Warm Current}

\author{
Sung Hyup You ${ }^{1 *}$ and Jong Hwan Yoon ${ }^{2}$ \\ ${ }^{1}$ Global Environment System Research Laboratory \\ National Institute of Meteorological Research, KMA, Seoul 156-720, Korea \\ ${ }^{2}$ Research Institute for Applied Mechanics \\ Kyushu University, Fukuoka 812-8581, Japan
}

\begin{abstract}
A model of the current and seasonal volume transport in the East China Sea was used to investigate the origin of the Tsushima Warm Current (TSWC). The modeled volume transport field suggested that the current field west of Kyushu $\left(30^{\circ}-32^{\circ} \mathrm{N}\right)$ was divided into two regions, R1 and R2, according to the bottom depth. R1 consisted of the Taiwan Warm Current (TWWC) region and the mixed Kuroshio-TWWC (MKT) water region, while R2 was the modified Kuroshio water (MKW) region west of Kyushu. The MKW branched from the Kuroshio and flowed into the Korea/Tsushima Straits through the Cheju-Kyushu Strait, contributing $41 \%$ of the annual mean volume transport of the TSWC. The TWWC and MKT water flowed into the Korea/Tsushima Straits through the Cheju-Kyushu and Cheju Straits, contributing 32\% and $27 \%$ of the volume transport, respectively. The maximum volume transport of the MKW was $53 \%$ of the total volume transport of the TSWC in November, while the maximum volume transport of the water in the $\mathrm{R} 1$ region through the Cheju-Kyushu Strait was $41 \%$ in July. Hence, there were two peaks per year of volume transport in the TSWC.
\end{abstract}

Key words : Tsushima Warm Current (TSWC), Taiwan Warm Current (TWWC), Mixed Kuroshio-Taiwan Warm Current (MKT), Modified Kuroshio Water (MKW)

\section{Introduction}

In the 1970s, the circulation in the East China Sea (ECS) was believed to consist of three main currents: the Kuroshio, the Tsushima Warm Current (TSWC), and the Yellow Sea Warm Current (YSWC; Nitani 1972). The Kuroshio enters the ECS through the Eastern Taiwan Channel (ETC), flows northeastward along the shelf slope, and exits through the Tokara Strait, after turning eastward near $30^{\circ} \mathrm{N}$. The TSWC flows into the East/Japan Sea (EJS) through the Korea/Tsushima (K/T) Straits, and the YSWC flows into the Yellow Sea south of Cheju Island.

In recent years, improved technologies for measuring currents and high-resolution numerical circulation models have increased our understanding of the current system in

\footnotetext{
*Corresponding author. E-mail : shyou@metri.re.kr
}

the ECS. It has been determined that the circulation in the ECS consists of the Kuroshio, the TSWC, the YSWC, the Taiwan Warm Current (TWWC), the Kuroshio Branch Current North of Taiwan (KBCNT), and the Kuroshio Branch Current West of Kyushu (KBCWK; Ichikawa and Beardsley 2002).

This study continues the effort to increase our understanding of the circulation in the ECS. Specifically, we investigated the seasonal variations of the circulations and water masses in the ECS, with a special focus on the origin of the TSWC. A high-resolution Pacific Ocean Model with realistic bottom topography was used that was free from boundary conditions for all straits in the ECS, as well as the $\mathrm{K} / \mathrm{T}$ Straits.

The origin of the TSWC has been the focus of many studies. These studies have contributed to our understanding of the circulation of the ECS itself, the Yellow Sea (YS), and the EJS. Two hypotheses on the origin of 
TSWC have been proposed. The first is that the TSWC is a continuation of the $\mathrm{KBCWK}$ that branches from the Kuroshio southwest of Kyushu (Kondo 1985; Lie and Cho 1994). The second is that the TSWC is a continuation of the TWWC flowing over the mid-shelf in the ECS (Beardsley et al. 1985; Fang et al. 1991). Currently, neither of these hypotheses can be discounted. This could be because of a lack of observational and numerical studies of the seasonal and vertical changes of horizontal circulation patterns in the ECS shelf region. It could also be due to the confusion about the northeastward current in the southwest ECS shelf region. In particular, it is unclear whether this region contains only the TWWC, or both the TWWC and the KBCNT.

Isobe (1999) suggested that the TSWC originates close to the Taiwan Strait in all seasons except autumn. Isobe (1999) used a diagnostic model that included long-term observed hydrographic and wind data, but did not incorporate the Kuroshio. However, he noted that evaluation of the amount of water exchange with the Kuroshio is very important for clarifying the origin of the TSWC water mass, as well as the origin of the volume transport. As An (1985) suggested, the incorporation of the Kuroshio may change our knowledge of circulation in the ECS significantly. Lin et al. (2001) concluded from their surface current data that in the cold half of the year, the KBCWK is the sole source of the TSWC, while in the warm half of the year, the TSWC has multiple sources: the KBCWK, the TWWC, the KBCNT, and the currents transporting Changjiang River Diluted Water (CRDW) and mixed water in the northern ECS. Guo et al. (2001) found via a tracer experiment that the TSWC is supplied by three sources: the TWWC, the KBCNT, and the KBCWK. They also found that it has different sources at different depths. Although various suggestions have been proposed, the origin of the TSWC and its physical characteristics remain unclear.

Many previous studies of the ECS have shown different patterns, as a result of their differing model conditions, uncertainties about sea surface conditions related to wind forcing and hydrographic input data, and difficulties in reasonable inflow and outflow conditions. Recent regional high-resolution three-dimensional numerical circulation models using realistic topography and boundary forcing have provided new insights into circulation in the ECS. The Pacific Ocean Model used in this study incorporated all of these factors and simulated a reasonable circulation pattern in the ECS.

In addition, ferryboat-mounted ADCP data (Takikawa et al. 2005) have shown that the volume transport through the Tsushima Strait has strong seasonal variation, with double peaks from spring to autumn. In this study, a Lagrangian drifter model using simulated high-resolution current fields was used to investigate the origin and double peak transport of the TSWC.

\section{Model}

The Research Institute for Applied Mechanics (RIAM) Ocean Model (RIAMOM) used in this study was a primitive general ocean circulation model with a free surface developed by Lee and Yoon (1994) at RIAM. The model assumed Boussinesq hydrostatic balance and solved the three-dimensional, non-linear, free-surface, primitive equations with the Arakawa B-grid system. The "slant advection" effect was incorporated into the model to represent the vertical advection of horizontal momentum at the bottom topography as accurately as possible (Ishizaki and Motoi 1999). The model also used an improved advection scheme for tracers, i.e., the modified split quadratic upstream interpolation for convective kinematics scheme (MSQUICK; Webb et al. 1998), in both horizontal and vertical directions.

The model covered the Pacific Ocean from $95^{\circ} \mathrm{E}$ to $70^{\circ} \mathrm{W}$ and from $50^{\circ} \mathrm{S}$ to $65^{\circ} \mathrm{N}$ (Fig. 1). The horizontal grid intervals were $1 / 12^{\circ}$ in both latitude and longitude, and the number of vertical levels was 70 . The vertical grid intervals were $10-125 \mathrm{~m}$ for depths of 0 to $2,420 \mathrm{~m}$, and $200-250 \mathrm{~m}$ for depths greater than 2,420 m (Table 1). The bottom topography of the model was based on the National Geophysical Data Center ETOPO5 with 5-min resolution.

Biharmonic horizontal diffusion was used for both momentum and tracers. The coefficients were $8.0 \times 10^{17}$ $\mathrm{cm}^{4} / \mathrm{s}$ for momentum, and $8.0 \times 10^{16} \mathrm{~cm}^{4} / \mathrm{s}$ for tracers. A mixed-layer model (Noh and Kim 1999; Noh et al. 2002) was applied to represent vertical mixing.

The model was integrated from a state of rest, with a climatological mean temperature and salinity distribution according to the World Ocean Atlas (WOA) 94 (Levitus et al. 1994; Levitus and Boyer 1994). It was forced by the monthly mean NCEP wind stress from the period 19792001. To prescribe the heat flux at the surface, a combined boundary condition expressed as

$$
Q=Q^{*}+\rho C_{P} \Delta z_{1}\left(T_{S}^{*}-T_{S}\right) / \tau
$$

Barnier et al. (1995) was used. In (1), $Q^{*}$ is the net heat flux of NCEP, $T_{S}^{*}$ is the sea surface temperature data from the WOA 94 (Levitus and Boyer 1994), $\tau$ is the restoring 


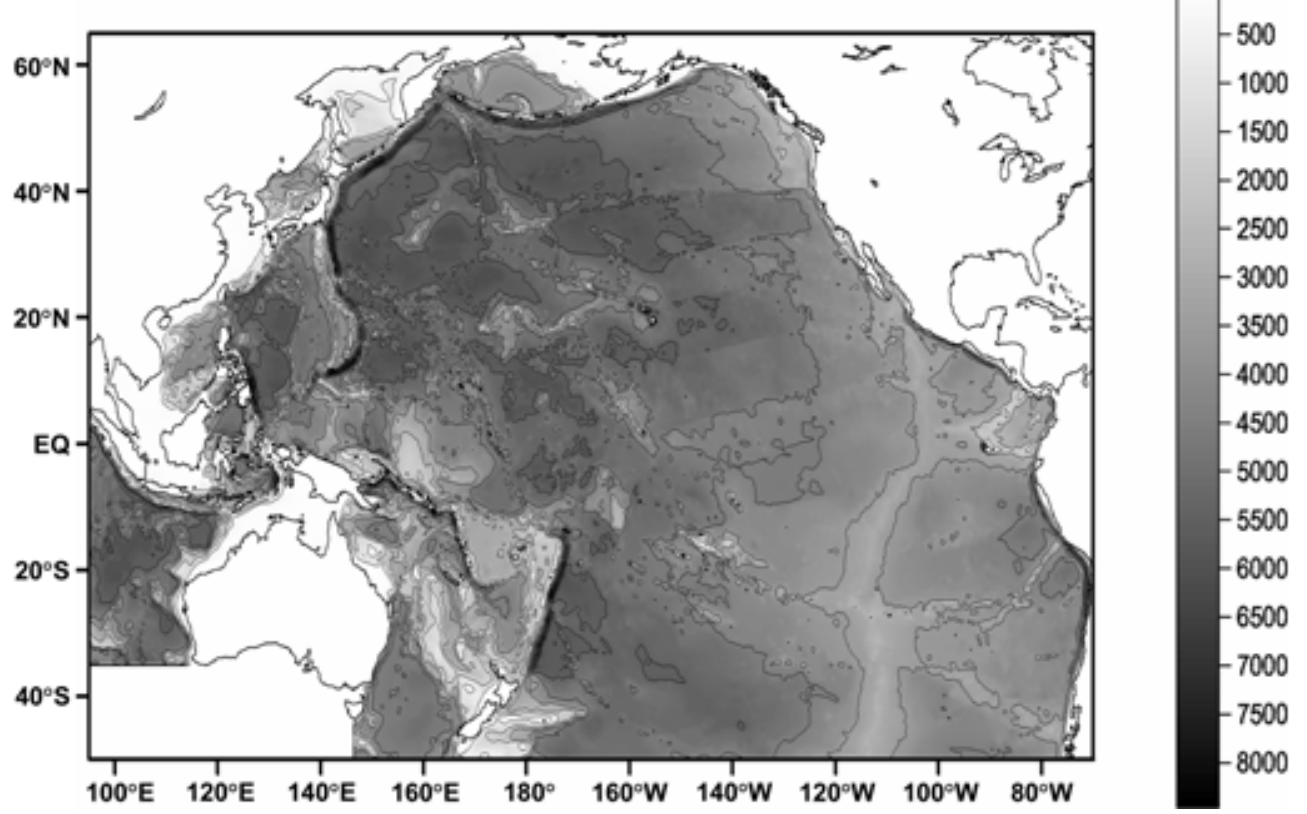

Fig. 1. Model domain and topography. Depths are in meters. The contour interval is $1000 \mathrm{~m}$.

Table 1. Depths of the layer thicknesses and levels used in the model

\begin{tabular}{ccc}
\hline Vertical Levels & Thickness of level & Depth of bottom \\
\hline $1-9$ & 10 & 90 \\
10 & 15 & 105 \\
$11-13$ & 20 & 165 \\
$14-15$ & 25 & 215 \\
$16-17$ & 30 & 275 \\
$18-20$ & 40 & 395 \\
$21-25$ & 50 & 645 \\
$26-30$ & 60 & 945 \\
$31-35$ & 75 & 1320 \\
$36-40$ & 95 & 1795 \\
$41-45$ & 125 & 2420 \\
46 & 200 & 2620 \\
47 & 230 & 2850 \\
$48-70$ & 250 & 8600 \\
\hline
\end{tabular}

time-scale (30 days), $\rho$ is the density, $C_{P}$ is the specific heat of seawater, and $\Delta z_{1}$ is the thickness of the first layer of the model. For the surface forcing (momentum and heat flux), climatological monthly mean data were linearly interpolated to provide values at each time step. The surface salinity was restored to the climatological value of the WOA 94 seasonal salinity data (Levitus et al. 1994) with a restoring time scale of 10 days.

To maintain the deep-water properties of the South Pacific region, the temperature at the southern boundary was restored to the climatological monthly mean tem- perature and salinity provided in the WOA 94 (Levitus et al. 1994; Levitus and Boyer 1994), with a time constant of 10 days. In the interior, conditions were restored to the climatological mean temperature and salinity data of the WOA 94 at levels deeper than 2,000 $\mathrm{m}$ with a longer time constant (1 year), to reduce spin-up computational time. The model was integrated for 25 years, and the last 5 years were analyzed.

\section{Results}

\section{East China Sea Circulation and Transport}

The 5-year mean of circulation at depths of 5 and $45 \mathrm{~m}$ in the ECS for the $1 / 12^{\circ}$ model is shown in Fig. 2. The model circulation generally appeared similar to the annual mean surface current field. In the model current fields in the southwestern ECS, the Kuroshio penetrated into the ECS, crossing the strait east of Taiwan. It then flowed northeastward along the ECS's continental shelf break, while the TWWC flowed into the ECS through the Taiwan Strait. Current measurements in the Taiwan Strait (Chuang 1986) showed that the TWWC exists in both summer and winter, with a northward annual mean current of about $27 \mathrm{~cm} / \mathrm{s}$. Qiu and Imasato (1990) obtained a long-term average of the surface velocity field in the ECS using GEK data and observed the KBCNT, which separates from the Kuroshio just after entering the ECS through the Eastern Taiwan Channel. In our model, the KBCNT turned 

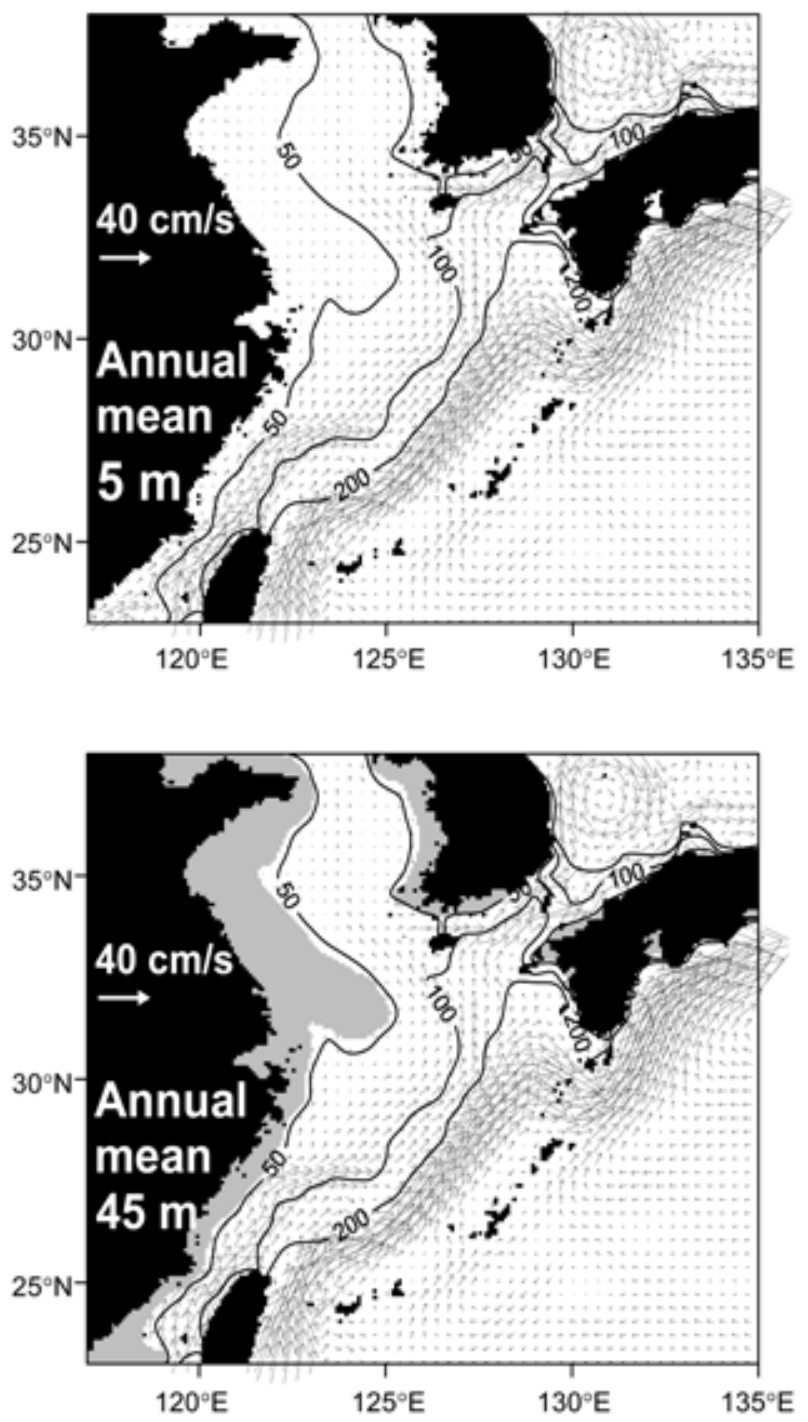

Fig. 2. Annual mean sea surface velocity fields at depths of 5 and $45 \mathrm{~m}$ in the model. The contours indicate $50-, 100-$, and $200-\mathrm{m}$ isobaths.

to the east to rejoin the main stream of the Kuroshio (Fig. 2).

With a width of $100-120 \mathrm{~km}$, the main Kuroshio stream flowed northeastward in the ECS along the continental shelf break and slope, deeper than the 200-m isobath, and flowed out through the Tokara Strait. A branched current, the KBCWK, appeared to flow northward after separating from the main Kuroshio stream southwest of Kyushu near $31^{\circ} \mathrm{N}, 128^{\circ} \mathrm{E}$ (Fig. 2). The KBCWK crossed the $200-\mathrm{m}$ isobath and flowed into the K/T Straits through the ChejuKyushu Strait.

By analyzing trajectories of surface drifters, Lie and Cho (1994) and Lie et al. (1998) proposed the existence of a branched current of the Kuroshio west of Kyushu (i.e., the KBCWK) that flows into the continental shelf of the ECS. They noted that the northward-flowing KBCWK separated from the Kuroshio around $29.5^{\circ} \mathrm{N}, 127.5^{\circ} \mathrm{E}$ with speeds of $30 \mathrm{~cm} / \mathrm{s}$, and that an anti-cyclonic warm eddy of $100-\mathrm{km}$ scale was found southwest of Kyushu. In addition, Lie and Cho (1994) and Lie et al. (1998) used hydrographic surveys of the northeastern ECS to propose that the KBCWK is the main source of the TSWC. The origin of the TSWC is discussed in more detail below.

From the model current fields in Fig. 2, it appears that flows located approximately between the 100-m and 200$m$ isobaths in the ECS merged into the K/T Straits through the Cheju-Kyushu Strait, and eventually into the EJS. The flows approximately between the 50-m and 100-m isobaths originated in the Taiwan Strait. They slowed downstream and bifurcated into two flows after Cheju Island. One of these flows turned eastward and passed through the Cheju Strait, and the other (the YSWC) flowed into the YS. Analyses of recent hydrographic data have shown that the mean surface current turns clockwise around Cheju Island, rather than flowing into the YS (Lie 1986; Kim et al. 1991; Lie et al. 1998, 2000). The current turning into and through the Cheju Strait is called the Cheju Warm Current (Lie et al. 1998, 2000).

Annual mean transports through major straits in the ECS, estimated from the model of this study and observations, are presented in Fig. 3. The seasonal variation of simulated volume transports was investigated at each channel for comparison to previous observations in the same regions (Fig. 4). The monthly and annual mean transports through the main straits of the ECS were calculated and are listed in Table 2.

The maximum and minimum modeled transport values were $3.39 \mathrm{~Sv}$ in July and $1.50 \mathrm{~Sv}$ in January, respectively (Fig. 4a). Although the modeled volume transport through the Taiwan Strait was slightly greater than the observed value, the seasonal volume transport through the Taiwan Strait in summertime was higher than that in wintertime. This was consistent with observations by Fang et al. (1991). The seasonal transport through the ETC in the model reached a maximum of $24.88 \mathrm{~Sv}$ in January and a minimum of $18.20 \mathrm{~Sv}$ in August, with an annual mean value of about $21.68 \mathrm{~Sv}$ (Fig. 4b). The largest volume transport of the model was in January. The modeled transport through the Tokara Strait varied from 22.60 Sv in November to $30.36 \mathrm{~Sv}$ in July, with an annual mean of $27.33 \mathrm{~Sv}$ (Fig. 4c). The seasonal volume transport of the model showed a maximum in July and a minimum in November. This was inconsistent with the observations of Ichikawa and Beardsley (1993). 


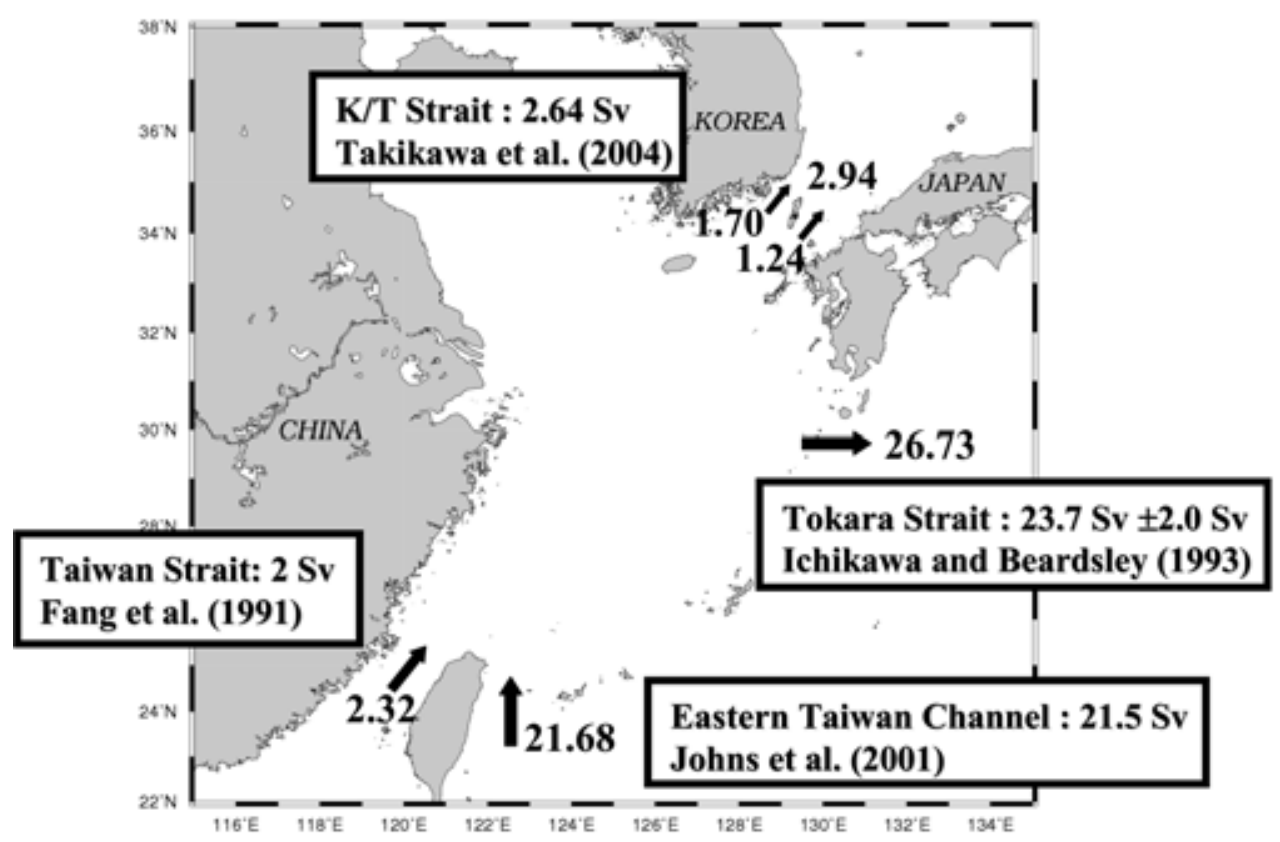

Fig. 3. Modeled annual mean volume transports through the major straits in the ECS. The observed annual mean volume transports are shown in the box (units are $\mathrm{Sv}=10^{6} \mathrm{~m}^{3} / \mathrm{s}$ ).
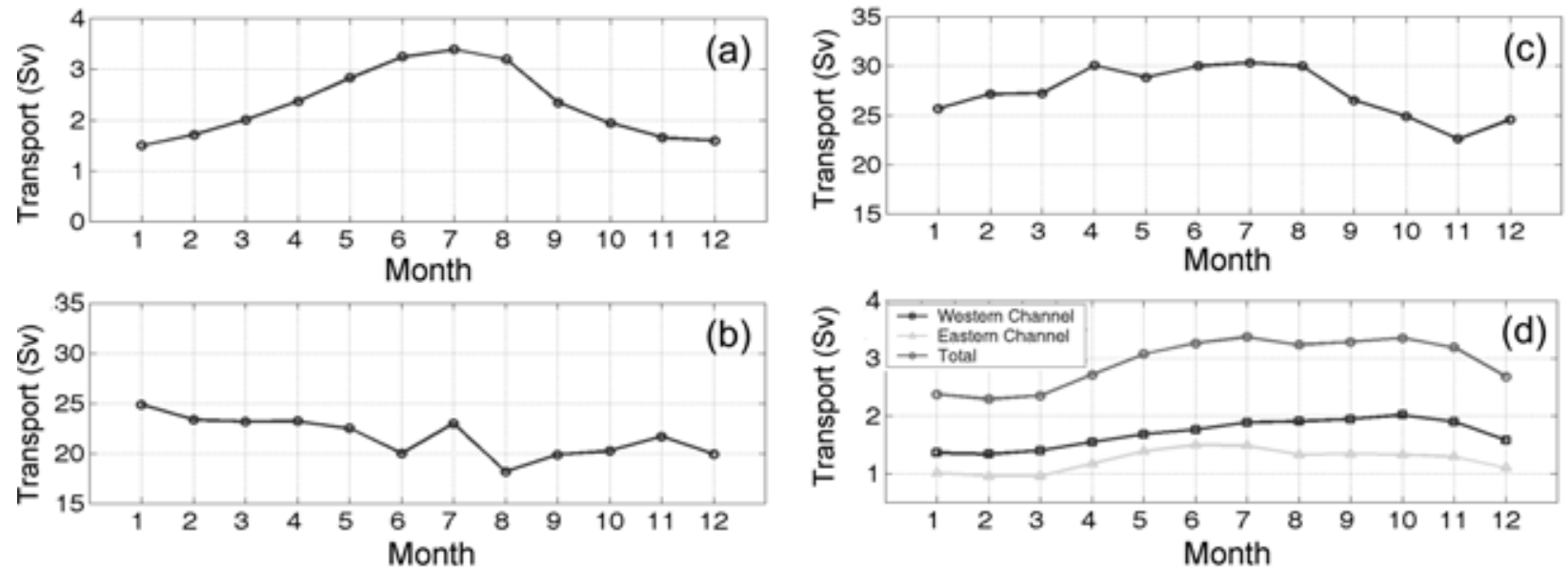

Fig. 4. Seasonal volume transport through the (a) Taiwan Strait, (b) Eastern Taiwan Channel, (c) Tokara Strait, and (d) Korea/Tsushima Straits.

Takikawa et al. (2005) obtained data using a shipmounted acoustic Doppler current profiler (ADCP) on a ferryboat regularly crossing the Tsushima Strait from February 1997 onwards. They found that the volume transport through the Tsushima Strait had strong seasonal variation, with a minimum in January and two maxima (double peaks) from spring to autumn. The transport value averaged over the observation period was approximately $2.64 \mathrm{~Sv}$. The volume transports through the western and eastern channels were $1.55 \mathrm{~Sv}$ and $1.10 \mathrm{~Sv}$, respectively.

In the model, the annual mean volume transport trough the K/T Straits was $2.94 \mathrm{~Sv}$, and transports through the western and eastern channels were $1.70 \mathrm{~Sv}$ and $1.24 \mathrm{~Sv}$, respectively. The peculiar double-peaked variation in transport that was observed in July and October (Takikawa et al. 2005) was also found in the model (Fig. 4d). The large volume transports through the eastern channel from May to July in the model were remarkably similar to observational results.

\section{Lagrangian Drifter Experiments}

Hofmann et al. (1991) calculated three-dimensional trajectories of model drifters with an integration period of 1 year, using a fourth-order Runge-Kutta scheme. The 
Table 2. Volume transports through major straits of the northwestern Pacific in the model (units are $\mathrm{Sv}=10^{6} \mathrm{~m}^{3} / \mathrm{s}$ )

\begin{tabular}{cccccc}
\hline \multirow{2}{*}{$\begin{array}{c}\text { Strait } \\
\text { Month }\end{array}$} & $\begin{array}{c}\text { Taiwan } \\
\text { Strait }\end{array}$ & $\begin{array}{c}\text { Eastern } \\
\text { Taiwan } \\
\text { Channel }\end{array}$ & $\begin{array}{c}\text { Tokara } \\
\text { Strait }\end{array}$ & \multicolumn{2}{c}{$\begin{array}{c}\text { Korea/Tsushima } \\
\text { Straits }\end{array}$} \\
\hline Jan. & 1.50 & 24.88 & 25.71 & 1.36 & 1.02 \\
Feb. & 1.71 & 23.36 & 27.15 & 1.34 & 0.95 \\
Mar. & 2.01 & 23.19 & 27.26 & 1.40 & 0.95 \\
Apr. & 2.37 & 23.24 & 30.05 & 1.55 & 1.17 \\
May & 2.83 & 22.52 & 28.86 & 1.69 & 1.39 \\
Jun. & 3.25 & 20.00 & 29.99 & 1.76 & 1.50 \\
Jul. & 3.39 & 22.98 & 30.36 & 1.89 & 1.48 \\
Aug. & 3.19 & 18.20 & 29.99 & 1.91 & 1.33 \\
Sep. & 2.35 & 19.87 & 26.54 & 1.94 & 1.34 \\
Oct. & 1.94 & 20.24 & 24.92 & 2.02 & 1.34 \\
Nov. & 1.66 & 21.68 & 22.60 & 1.90 & 1.29 \\
Dec. & 1.59 & 19.95 & 24.56 & 1.59 & 1.10 \\
\hline Mean & 2.32 & 21.68 & 27.33 & 1.70 & 1.24 \\
\hline
\end{tabular}

horizontal components of velocity were interpolated using the bicubic interpolation from 16 neighboring grid points. The vertical components of velocity were linearly interpolated. In our study, a simulated drifter was released once a day for a month in each season at each grid point through the Taiwan Strait and the ETC. The positions of the drifters were then recorded every 6 hours for 1 year.

The trajectories of drifters released at depths of 5 and $45 \mathrm{~m}$ in the Taiwan Strait in February and August are shown in Fig. 5. Drifters released from the Taiwan Strait barely moved into the region of the KBCNT or the region deeper than the $200-\mathrm{m}$ isobath south of $30^{\circ} \mathrm{N}$. However, some moved into the deeper region west of Kyushu and north of $30^{\circ} \mathrm{N}$.

The trajectories of drifters released at depths of 5 and $45 \mathrm{~m}$ in the ETC in February and August are shown in Fig. 6. Drifters occupied almost all regions deeper than $100 \mathrm{~m}$, but barely intruded into the region shallower than $100 \mathrm{~m}$. However, very few drifters entered the region

\section{Drifters released at $5 \mathrm{~m}$ depth in Feb. Drifters released at $5 \mathrm{~m}$ depth in Aug.}

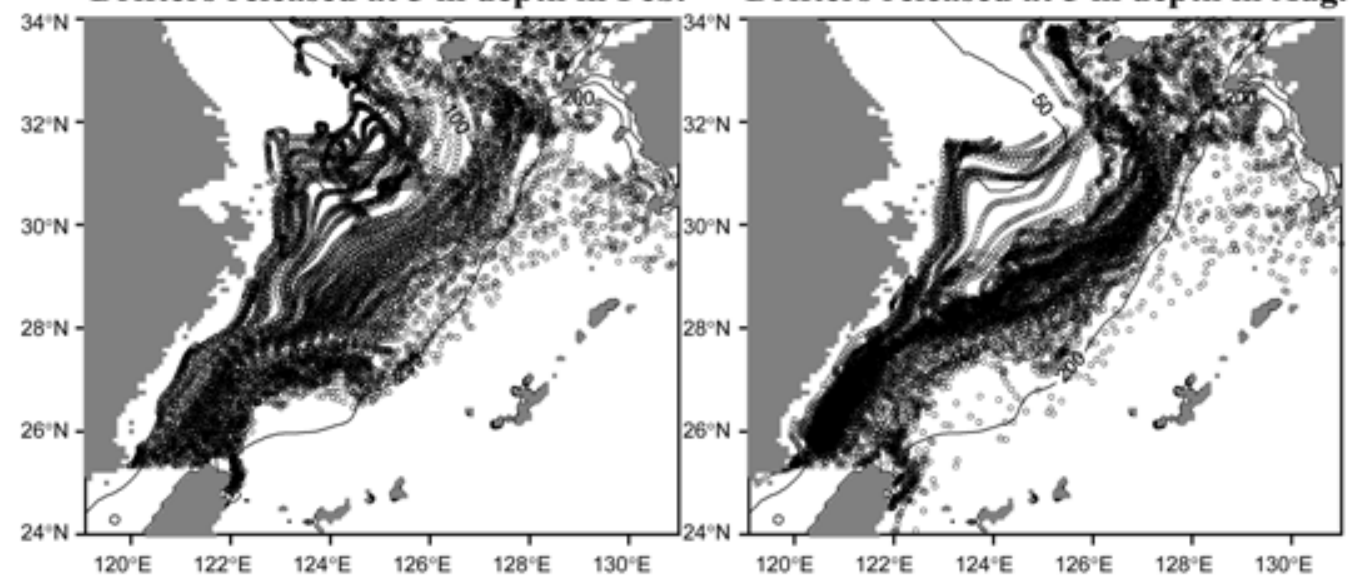

Drifters released at $45 \mathrm{~m}$ depth in Feb. Drifters released at $45 \mathrm{~m}$ depth in Aug.

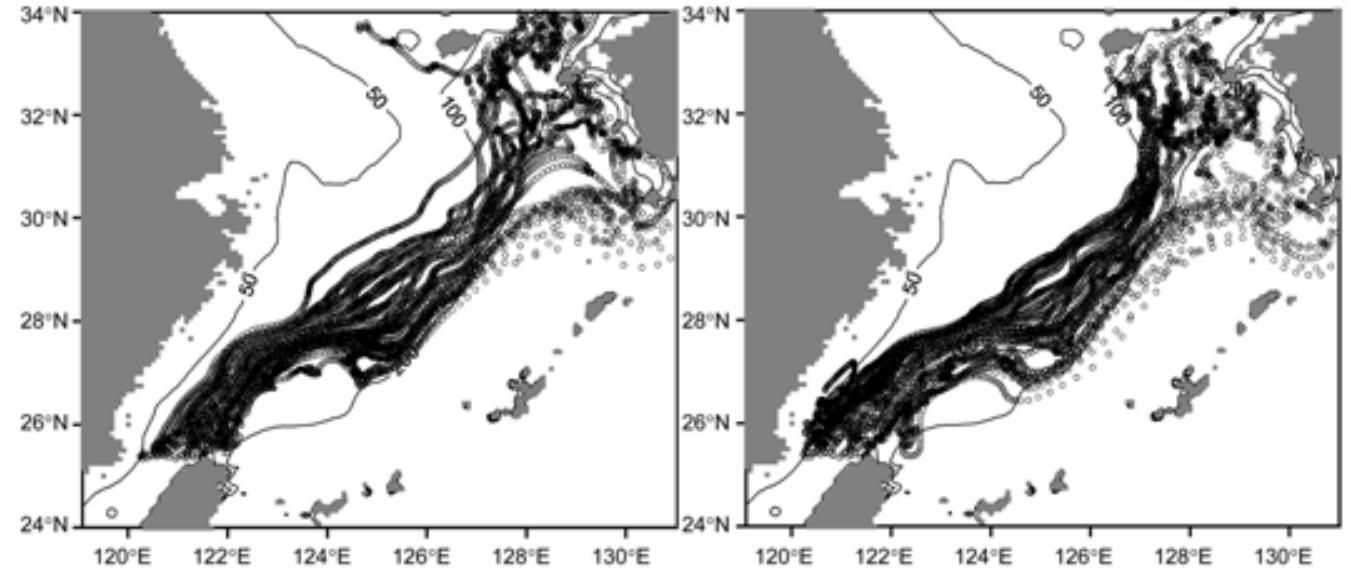

Fig. 5. Trajectories of simulated drifters released at depths of 5 and $45 \mathrm{~m}$ in the Taiwan Strait in February and August during 1 year. 
Drifters released at $5 \mathrm{~m}$ depth in Feb. Drifters released at $5 \mathbf{m}$ depth in Aug.

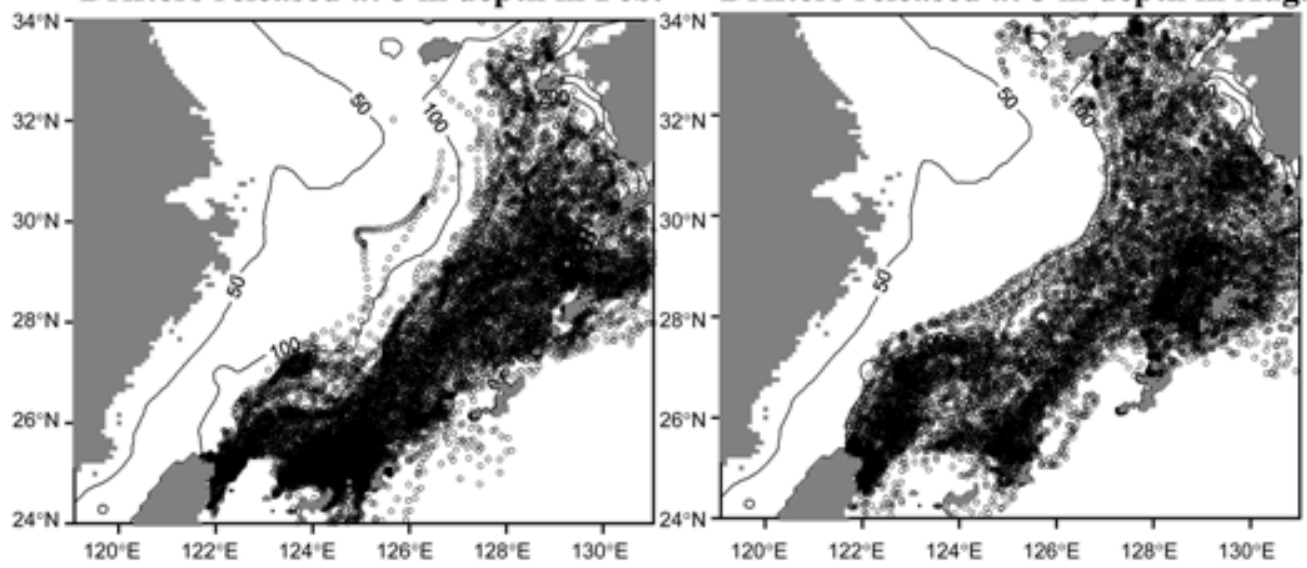

Drifters released at $45 \mathrm{~m}$ depth in Feb. Drifters released at $45 \mathrm{~m}$ depth in Aug.

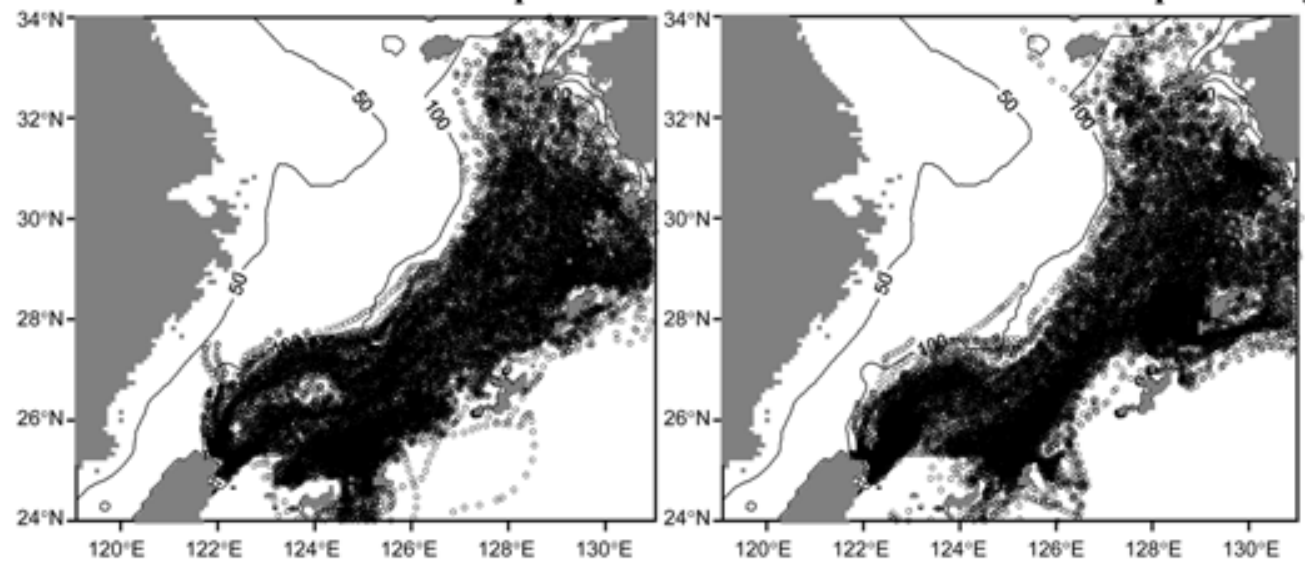

Fig. 6. Trajectories of simulated drifters released at depths of 5 and $45 \mathrm{~m}$ in the Eastern Taiwan Channel in February and August during 1 year.

south of Cheju Island (approximately $32^{\circ} \mathrm{N}$ ), where the depth was greater than $100 \mathrm{~m}$. The complex pattern around this region is discussed next.

Several conclusions may be drawn from these drifter experiment results. First, the region approximately between $100 \mathrm{~m}$ and $200 \mathrm{~m}$ depth south of $30^{\circ} \mathrm{N}$ in the ECS, with the exception of the region of the KBCNT northeast of Taiwan, appeared to be a mixing region between the Kuroshio and the TWWC. Hence, this region is named the mixed Kuroshio-TWWC (MKT) region. Second, the TWWC could not intrude into the KBCNT, but the Kuroshio could. Hence, the KBCNT region is defined as the Kuroshio water region. Third, the Kuroshio water intruded into the region shallower than $100 \mathrm{~m}$. The region between 50 and $100 \mathrm{~m}$ deep is therefore defined as the TWWC region. Fourth, the TWWC barely intruded into the region deeper than $200 \mathrm{~m}$ south of $30^{\circ} \mathrm{N}$. Hence this region is also defined as the Kuroshio water region. Fifth, the region deeper than $200 \mathrm{~m}$, north of $30^{\circ} \mathrm{N}$ and west of Kyushu, is defined as the region of Modified Kuroshio

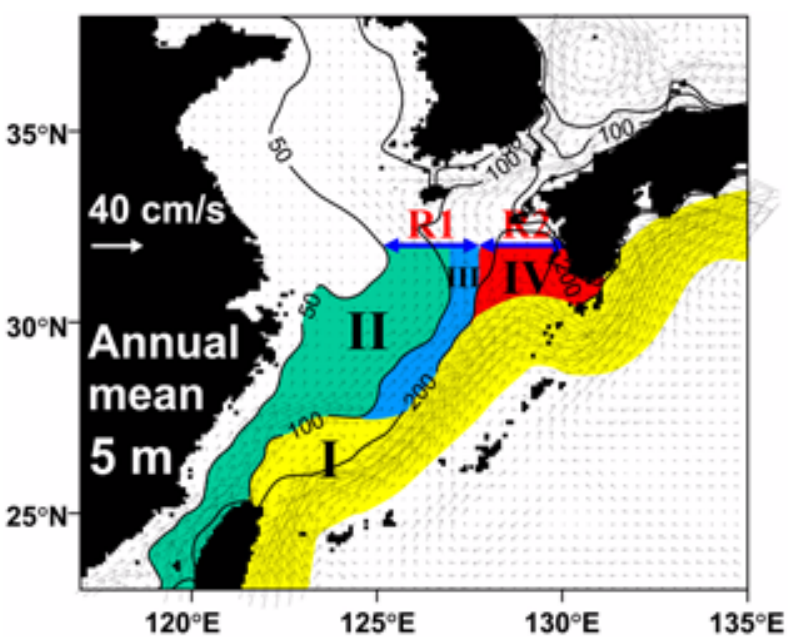

Fig. 7. Location of the water region combined with the current field at $5 \mathrm{~m}$ depth in the $1 / \mathbf{1 2}^{\circ}$ model. $\mathrm{R} 1$ and $R 2$ indicate the regions in Fig. 9. Region $I$ is the Kuroshio water region, Region II is the TWWC region, Region III is the mixed Kuroshio-TWWC region, and Region IV is the modified Kuroshio water region. 
water (MKW), which is formed by mixing between the Kuroshio water and the MKT water.

Fig. 7 shows the locations of these water regions. Region I is the Kuroshio water region, Region II is the
TWWC region, Region III is the MKT region, and Region IV is the MKW region. We use these conceptual classifications to describe the origin of the TWWC in the next chapter.

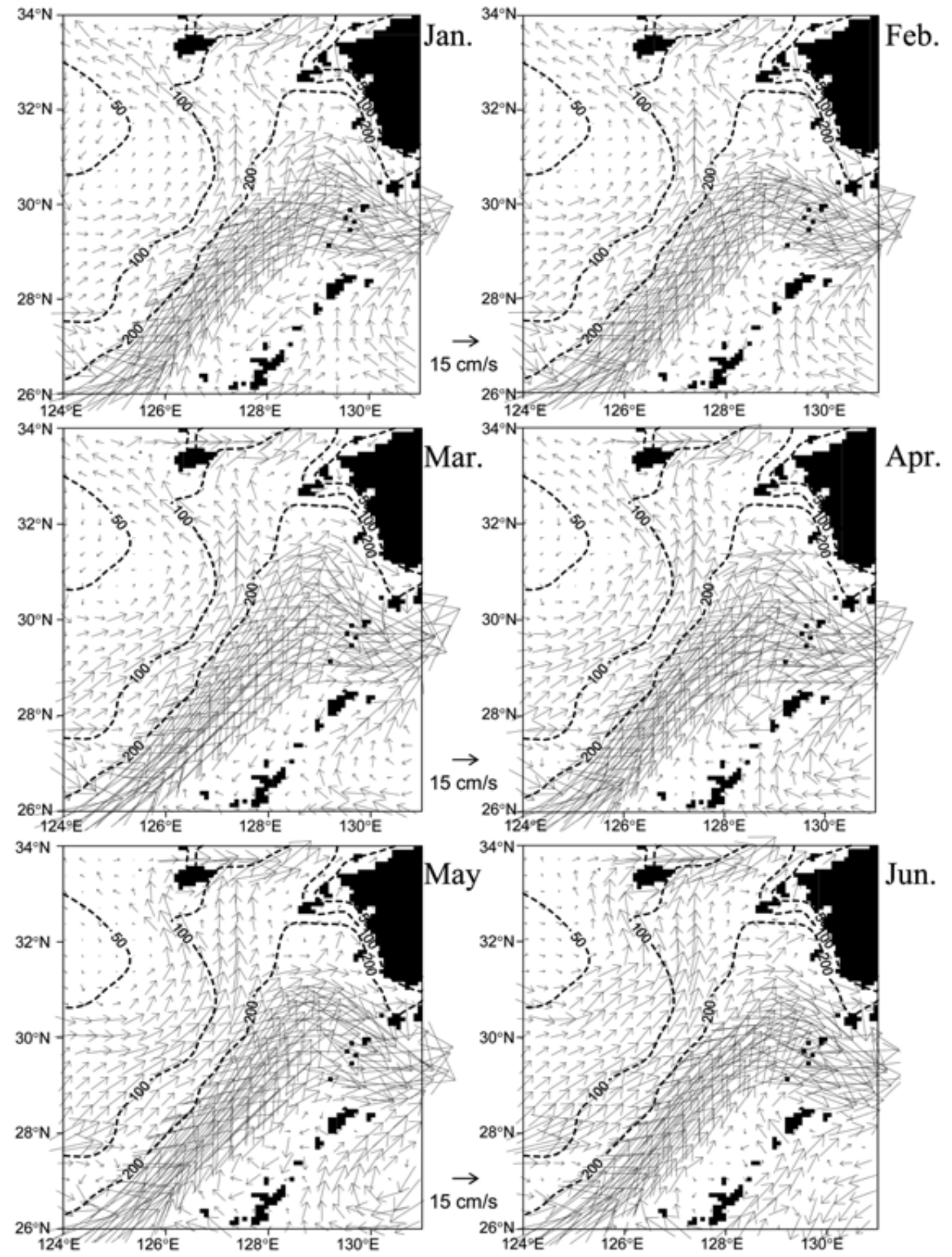

Fig. 8. Seasonal current fields southwest of Kyushu at $5 \mathrm{~m}$ depth. The dotted lines indicate the 50-, 100-, and 200-m isobaths. 


\section{Origin of the TWWC}

Fig. 8 shows the seasonal changes in the surface current west of Kyushu in the model. As can be seen, the northward current crossing the 200-m isobath from Region IV toward the K/T Straits developed strongly. From
September to February, this current branch from the Kuroshio developed into the $\mathrm{KBCWK}$ and flowed into the K/T Straits, feeding the TSWC. From March to May, the current fields west of Kyushu showed complex patterns, such as the cyclonic circulation west of Kyushu. From
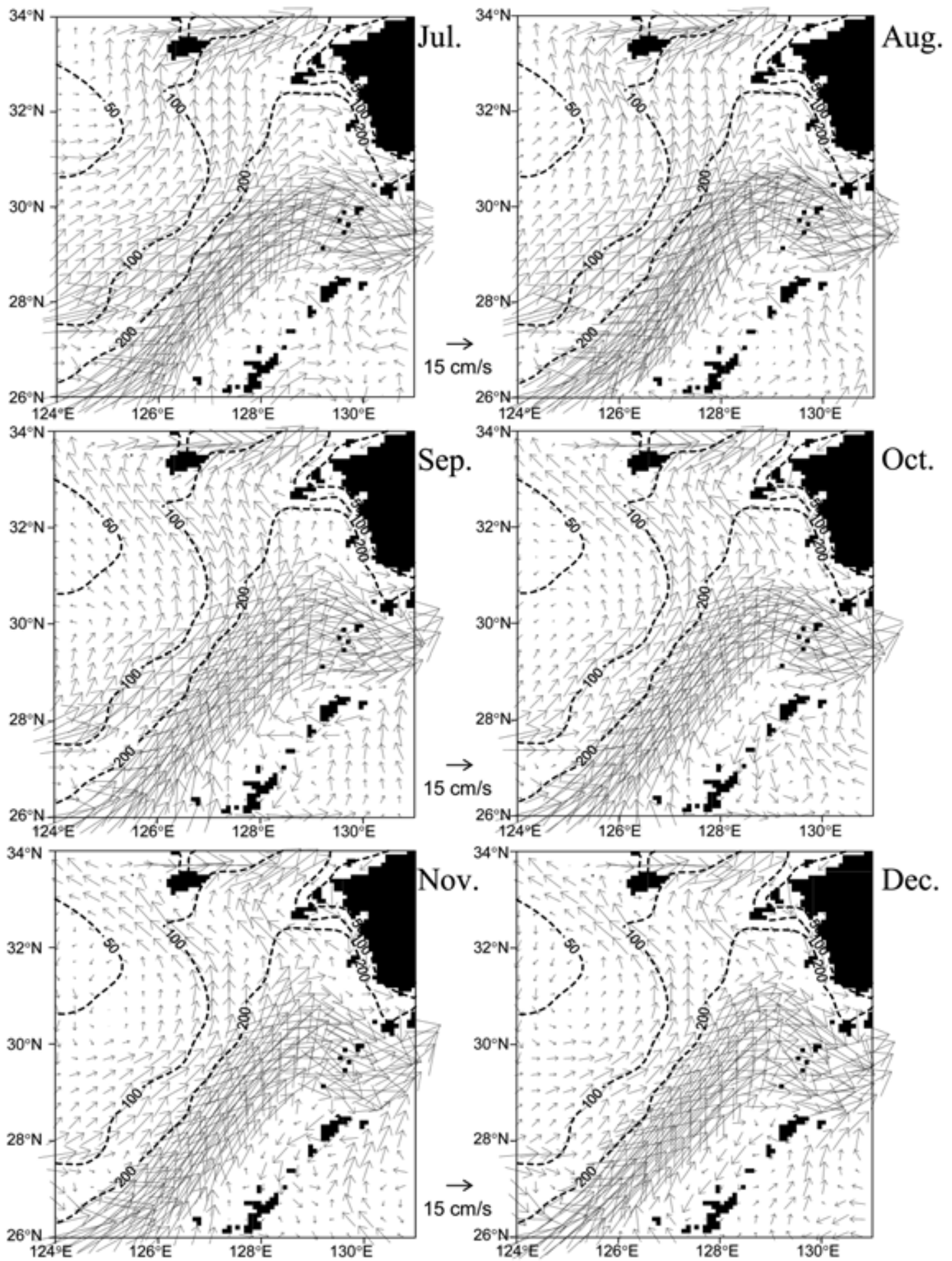

(Fig. 8. Continued) 
June to August, there was no significant northward current across the 200-m isobath west of Kyushu. Between depths
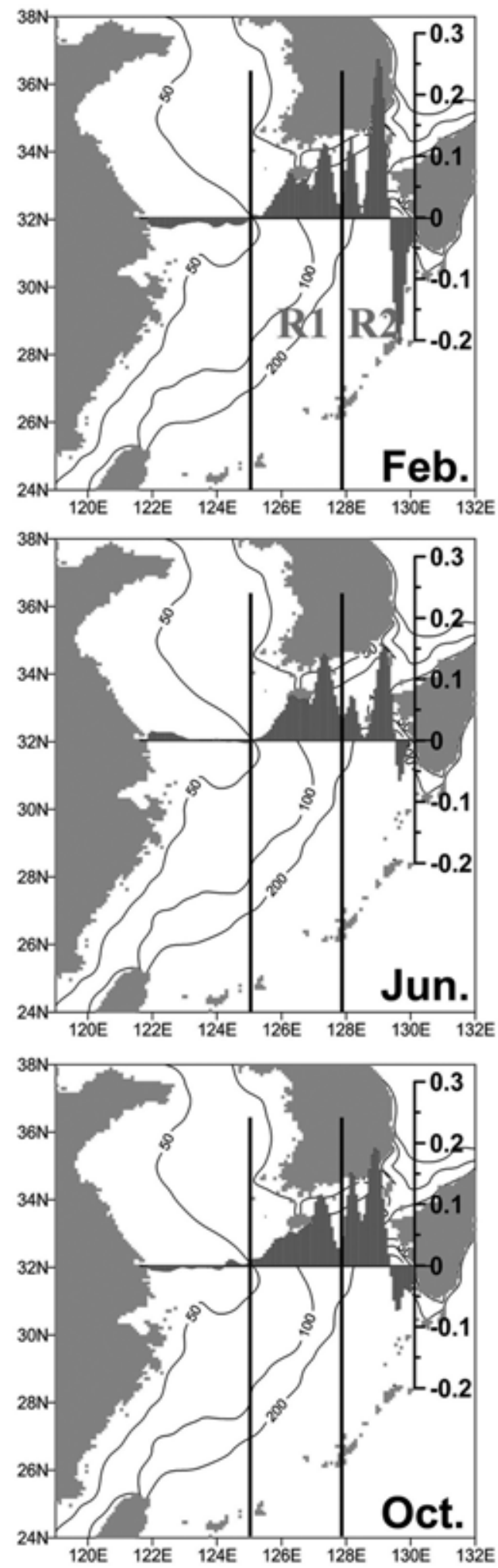

of $\sim 100$ and $200 \mathrm{~m}$, the current entered the K/T Straits through the Cheju-Kyushu Strait, feeding the TSWC.
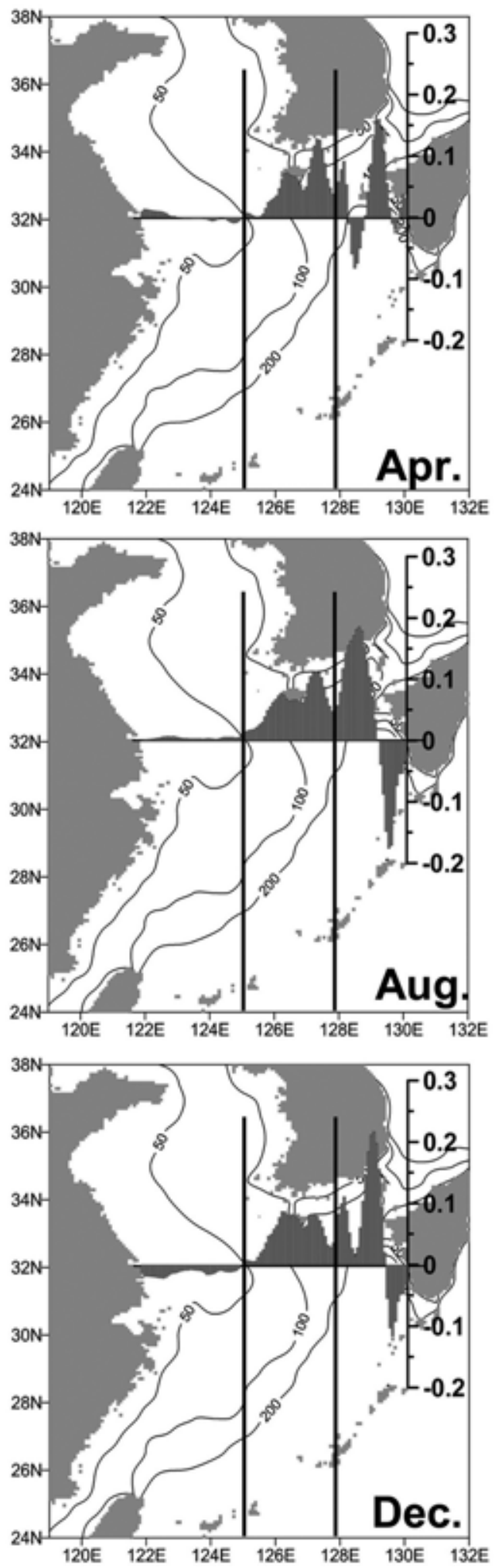

Fig. 9. Seasonal volume transport variations along the $32^{\circ} \mathrm{N}$ line (The boundaries of $\mathrm{R} 1$ and $\mathrm{R} 2$ are indicated by thick lines). 
Between depths of $\sim 50$ and $100 \mathrm{~m}$, part of the northward current turned to the east, flowing into the $\mathrm{K} / \mathrm{T}$ Straits through the Cheju Strait. The remaining part of the northward current flowed into the YS as the YSWC.

Fig. 9 shows the seasonal variations of model volume transport (VT) at each grid along the section of $32^{\circ} \mathrm{N}$ latitude. We divided the east section at $50 \mathrm{~m}$ depth into two regions, R1 and R2. According to the VT of the $32^{\circ} \mathrm{N}$ latitude line, Fig. 7 shows the locations of water regions (R1 and R2) extending to that line.

Regions R1 and R2 corresponded to the combined TWWC and MKT regions, and the MKW region, respectively. Along $32^{\circ} \mathrm{N}$, the boundary between R1 and R2 was located at $170 \mathrm{~m}$ depth around $127.8^{\circ} \mathrm{E}$, as determined by the VT profiles in Fig. 9 and the horizontal velocity fields shown in Fig. 8. Region R1 was located approximately between depths of 50 and $170 \mathrm{~m}$ (around $127.8^{\circ} \mathrm{E}$ ), and region $\mathrm{R} 2$ was located approximately between $127.8^{\circ} \mathrm{E}$ and the coast of Kyushu. The northward VT through the eastern part of region R1 may have entered the K/T Straits through the Cheju-Kyushu Strait, as implied by the surface current fields shown in Fig. 8. The current fields also indicated that part of the northward VT through the western part of region R1 entered the K/T Straits through the Cheju Strait. The remaining VT entered into the YS.

Although the depth of integrated northward VT through each grid section in region R2 generally changed sign in association with the recirculating southward flow along the coast of Kyushu, there was a seasonally varying net northward VT, which was attributed to the KBCWK.

The western part of R1 corresponded to Region 2 (the TWWC region), and the eastern part of R1 corresponded to Region 3 (the MKT region). However, it was difficult to determine the boundary between the TWWC region and the MKT water region in this study. Therefore, the northward VT through the eastern part of region R1 into the Cheju-Kyushu Strait was regarded as the sum of the VTs of the TWWC and the MKT through the eastern part of R1. To calculate these latter VTs, the net northward VT through R2 (i.e., the KBCWK transport), was subtracted from the VT through the Cheju-Kyushu Strait. The VT through the Cheju Strait was partly due to the northward VT through the western part of R1.

Fig. 10 shows the seasonal VT changes through the Cheju Strait and the Cheju-Kysuhu Strait into the K/T Straits (upper panel). It also shows the seasonal VT changes 1) through the western part of R1 (the VTs of the TWWC and the MKT through the Cheju Strait), 2) through the eastern part of R1 (the VTs of the TWWC and
Table 3. Seasonal absolute and percentage volume transport through the Cheju Strait, the Cheju-Kyushu Section and the Korea/Tsushima Straits in the model (units are $\mathrm{Sv}=$ $\left.10^{6} \mathrm{~m}^{3} / \mathrm{s}[\%]\right)$

\begin{tabular}{ccccc}
\cline { 3 - 4 } Month & $\begin{array}{c}\text { Straits } \\
\text { Cheju Strait } \\
\text { (TWWC }+\end{array}$ & \multicolumn{2}{c}{ Cheju-Kyushu } & KW/T \\
\cline { 3 - 4 } MKT) & $\begin{array}{c}\text { TWC }+ \\
\text { MKT }\end{array}$ & MKW & Straits \\
\hline Jan. & $0.63(26.47)$ & $0.52(21.85)$ & $1.23(51.68)$ & 2.38 \\
Feb. & $0.62(27.07)$ & $0.64(27.95)$ & $1.03(44.98)$ & 2.29 \\
Mar. & $0.63(26.81)$ & $0.81(34.47)$ & $0.91(38.72)$ & 2.35 \\
Apr. & $0.73(26.84)$ & $1.03(37.87)$ & $0.96(35.29)$ & 2.72 \\
May & $0.75(24.43)$ & $1.27(41.37)$ & $1.05(34.20)$ & 3.07 \\
Jun. & $0.79(24.23)$ & $1.35(41.41)$ & $1.12(34.36)$ & 3.26 \\
Jul. & $0.89(26.41)$ & $1.40(41.54)$ & $1.08(32.05)$ & 3.37 \\
Aug. & $0.94(29.01)$ & $1.29(39.82)$ & $1.01(31.17)$ & 3.24 \\
Sep. & $0.92(27.96)$ & $1.04(31.61)$ & $1.33(40.43)$ & 3.29 \\
Oct. & $0.94(28.06)$ & $0.75(22.39)$ & $1.66(49.55)$ & 3.35 \\
Nov. & $0.91(28.53)$ & $0.56(17.55)$ & $1.72(53.92)$ & 3.19 \\
Dec. & $0.78(29.10)$ & $0.50(18.66)$ & $1.40(52.24)$ & 2.68 \\
Mean & $0.80(27.21)$ & $0.93(31.63)$ & $1.21(41.16)$ & 2.94 \\
\hline
\end{tabular}
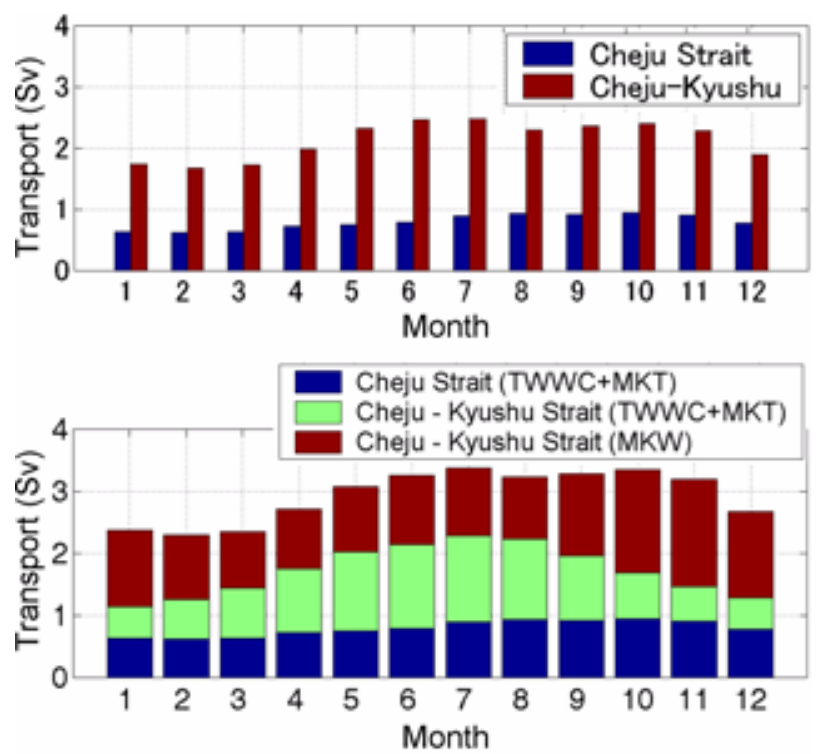

Fig. 10. Seasonal volume transport variations through the Cheju Strait and the Cheju-Kyushu section (upper panel). Additionally, seasonal volume transport variations of the TWWC and mixed Kuroshio-TWWC through the Cheju Strait and the Cheju-Kyushu Strait, and modified Kuroshio water through the Cheju-Kyushu Strait (lower panel).

the MKT through the Cheju-Kyushu Strait) and 3) of the KBCWK into the K/T Straits (lower panel). The VTs described are listed in Table 3.

Fig. 10 also shows that the VTs of the TWWC and the 
MKT through the Cheju-Kyushu Strait increased in summer, up to a maximum of $1.40 \mathrm{~Sv}$ in July. They decreased in winter, down to a minimum of $0.50 \mathrm{~Sv}$ in December. The VT of the KBCWK was lower between February and August, reaching a minimum of $1.12 \mathrm{~Sv}$, and higher between September and January, reaching a maximum of $1.72 \mathrm{~Sv}$ in November. The VT through the Cheju Strait changed slightly over the season, with a maximum of $0.94 \mathrm{~Sv}$ in October and a minimum of 0.62 $\mathrm{Sv}$ in February. The seasonal changes of the VTs implied that the VTs of the TWWC and the MKT through the Cheju-Kyushu Strait were the main sources $(1.40 \mathrm{~Sv}$, or $41 \%$, in July) of the VT of the TSWC in summer. The KBCWK became the main source $(1.72 \mathrm{~Sv}$, or $53 \%$, in November) in autumn, resulting in the double maximum of the total VT in July and October (lower panel of Fig. 10).

This VT double maximum was observed in the $\mathrm{K} / \mathrm{T}$ Strait (Takikawa et al. 2005), where the VT reaches its maximum in June and October. Cho (1995) estimated that the current through the Cheju Strait feeds $23-26 \%$ of the TSWC, a calculation in agreement with the model results.

\section{Conclusion}

The horizontal resolution of a numerical model greatly affects the path, current intensity, and vertical structure associated with the Kuroshio. Coarser models underestimate the baroclinic structure of the Kuroshio in the ECS. However, the other main currents in the ECS were similar to observations because of the high horizontal and vertical model resolution. Therefore, reproductions using a highresolution numerical model with realistic forcing and topography of the entire current system in the ECS are necessary to clarify the origin of the TSWC.

Using a realistic simulation of the current system in the ECS, the origin of the TSWC was investigated by Lagrangian drifter experiments. Drifter trajectories indicated that the modeled current field in the ECS was divided into four regions based on bottom depth. Region I was the Kuroshio water region deeper than $200 \mathrm{~m}$ south of $30^{\circ} \mathrm{N}$, region II was the TWWC region between depths of 50 and $100 \mathrm{~m}$, region III was the MKT region between depths of 100 and $200 \mathrm{~m}$ south of $30^{\circ} \mathrm{N}$ (excluding the KBCNT region), and Region IV was the MKW region deeper than $200 \mathrm{~m}$ north of $30^{\circ} \mathrm{N}$. The model results showed clear development of a northward current crossing the 200-m isobath west of Kyushu. From September to February, the northward current branch from the Kuroshio west of Kyushu developed as the $\mathrm{KBCWK}$, transporting the MKW of Region IV into the K/T Strait.

The modeled volume transport field suggested that the current field west of Kyushu $\left(30^{\circ}\right.$ to $\left.32^{\circ} \mathrm{N}\right)$ was divided into two regions, R1 and R2, based on bottom depth. Region R1 was the TWWC region plus the MKT water region, while region $\mathrm{R} 2$ was the $\mathrm{MKW}$ region west of Kyushu. The boundary between R1 and R2 was located at $170 \mathrm{~m}$ depth at around $127.8^{\circ} \mathrm{E}$. However, it was difficult to determine the boundary between the TWWC and the MKT regions in $\mathrm{R} 1$. The MKW that branched from the Kuroshio flowed into the K/T Strait through the ChejuKyushu Strait, giving $41 \%$ of the total contribution to the annual mean volume transport of the TSWC. The TWWC and MKT water flowed into the $\mathrm{K} / \mathrm{T}$ Straits through the Cheju-Kyushu Strait and the Cheju Strait, with 32\% and $27 \%$ contributions, respectively.

The model showed that the VT through the Cheju Strait changed slightly over a season, with a maximum of 0.94 $\mathrm{Sv}$ in October and a minimum of $0.62 \mathrm{~Sv}$ in February. The seasonal changes of the modeled VTs show that the VTs of the TWWC and the MKT through the Cheju-Kyushu Strait were the main sources ( $1.40 \mathrm{~Sv}$ or $41 \%$ in July) of the TSWC VT in summer, while the KBCWK was a main source (1.72 $\mathrm{Sv}$ or $53 \%$ in November) in autumn. This generated the double maximum in July and October in the TSWC VT annual cycle, which was similar to that observed by Takikawa et al. (2005).

The present trace experiments and conceptual use of the $\mathrm{R} 1$ and R2 regions were not able to provide direct quantitative evidence for the origin of TSWC. An analysis of water masses, particularly the amount of water exchange with the Kuroshio, should be attempted to resolve this. Such a quantitative analysis will be accomplished in the near future.

\section{Acknowledgements}

This study was performed as part of the Project for Sustainable Coexistence of Human, Nature, and the Earth, which is supported by the Ministry of Education, Culture, Sports, Science, and Technology of the Japanese government. All simulations were performed using the Earth Simulator. This paper was submitted as a part of the "Valuation on Precision Improvement of Surge Prediction System" series, which is supported by NIMR/KMA.

\section{References}

An, H.S. 1985. The numerical experiment on the circulation 
in the Yellow Sea and the East China Sea by means of the two layer model. J. Kor. Ear. Sci. Soc., 6, 43-48. (In Korean)

Barnier, B., L. Siefridt, and P. Marchesiello. 1995. Thermal forcing for a global ocean circulation model using a three-year climatology of ECMWF analyses. J. Mar. Sys., 6, 363-380.

Beardsley, R.C., R. Limeburner, H. Yu, and G.A. Cannon. 1985. Discharge of the Changjiang (Yangtze River) into the East China Sea. Cont. Shelf Res., 4, 7-76.

Cho, Y.K. 1995. Hydrographic and a hydraulic model of current in the Korea Strait. Ph.D. Thesis, Seoul National University, $142 \mathrm{p}$.

Chuang, W.S. 1985. Dynamics of subtidal flow in the Taiwan Strait. J. Oceanogr. Soc. Japan, 41, 65-72.

Chuang, W.S. 1986. A note on the driving mechanisms of current in the Taiwan Strait. J. Oceanogr. Soc. Japan, 42, 355-361.

Fang, G., B. Zhao, and Y. Zhu. 1991. Water volume transport through the Taiwan Strait and the continental shelf of the East China Sea measured with current meters. p. 345-348. In: Oceanography of Asian Marginal Seas, ed. by K. Takano. Elsevier, Amsterdam.

Guo, X., Y. Miyazawa, H. Hukuda, and T. Yamagata. 2001. Tracer experiments on the origin of the Tsushima Warm Current. p. 45-47. In: Proc. 11th PAMS/JECSS Workshop, Cheju, Korea, Apl. 11-13.

Hofmann, E.E., K.S. Hedstorm, J.R. Moisan, D.B. Haidvogel, and D.L. Mackas. 1991. Use of simulated drifter tracks to investigate general transport patterns and residence times in the coastal transition zone. J. Geophys. Res., 96(C8), 15041-15052.

Ichikawa, H. and R.C. Beardsley. 1993. Temporal and spatial variability of volume transport of the Kuroshio in the East China Sea. Deep Sea Res., 40, 583-605.

Ichikawa, H. and R.C. Beardsley. 2002. The current system in the Yellow and East China Seas. J. Oceanogr., 58, 77-92.

Ishizaki, H. and T. Motoi. 1999. Reevaluation of the Takano-Oonishi scheme for momentum advection of bottom relief in ocean models. J. Atmos. and Ocean. Tech., 16, 1994-2010.

Isobe, A. 1999. On the origin of the Tsushima Warm Current and its seasonality. Cont. Shelf Res., 19, 117-133.

Kim, K., H.K. Rho, and S.H. Lee. 1991. Water masses and circulation around Cheju-do in summer. J. Oceanol. Soc. Korea, 26, 262-277.
Kondo, M. 1985. Oceanographic investigations of fishing grounds in the East China and the Yellow Sea. Bull. Seikai Region. Fish. Res. Lab., 62, 19-55.

Lee, H.C. and J.H. Yoon. 1994. On the free surface OGCM. Proc. of Fall Meeting the Japan Oceanogr. Soc., 225226.

Levitus, S., R. Burgett, and T.P. Boyer. 1994. World ocean atlas, Vol. 3: Salinity. NOAA Atlas NESDIS, 3, 99 p.

Levitus, S. and T.P. Boyer. 1994. World ocean atlas, Vol. 4: Temperature. NOAA Atlas NESDIS, 4, 117 p.

Lie, H.-J. 1986. Summertime hydrographic features in the southeastern Hwanghae. Prog. Oceanogr., 17, 229-242.

Lie, H.-J. and C.-H. Cho. 1994. On the origin of the Tsushima Warm Current. J. Geophys. Res., 99, 25081-25091.

Lie, H.-J., C.-H. Cho, J.-H. Lee, P. Niller, and J.-H. Hu. 1998. Separation of the Kuroshio water and its penetration onto the continental shelf west of Kyushu. J. Geophys. Res., 103, 2963-2676.

Lie, H.-J., C.-H. Cho, J.-H. Lee, S. Lee, and Y. Tang. 2000. Seasonal variation of the Cheju Warm Current in the northern East China Sea. J. Oceanogr., 56, 197-211.

Lin, K., B. Guo, and Y. Tang. 2001. An analysis on observational surface current in the Yellow Sea and the East China Sea. p. 67-71. In: Proc. 11th PAMS/JECSS Workshop, Cheju, Korea, Apl. 11-13.

Noh, Y. and H.J. Kim. 1999. Simulations of temperature and turbulence structure of the oceanic boundary layer with the improved near surface process. J. Geophys. Res., 104, 15621-15634.

Noh, Y., C.J. Jang, T. Yamakata, P.C. Chu, and C.H. Kim. 2002. Simulation of more realistic upper-ocean processes from an OGCM with a new ocean mixed layer model. J. Phys. Oceanogr., 32, 1284-1307.

Qiu, B. and N. Imasato. 1990. A numerical study on the formation of the Kuroshio Counter Current and the Kuroshio Branch Current in the East China Sea. Cont. Shelf Res., 10, 165-184.

Takikawa, T., J.H. Yoon, and K.D. Cho. 2005. The Tsushima Warm Current through the Tsushima Straits estimated from ADCP data by ferryboat. J. Phys. Oceanogr., 35, 1154-1168.

Webb, D.J., B.A. de Cuevas, and C.S. Richmond. 1998. Improved advection scheme for ocean models. J. Atmos. Ocean. Tech., 15, 1171-1187.

Received May 26, 2008 Accepted Jun. 11, 2008 